Research Article

\title{
Development and Evaluation of Oral Fast Disintigreting Tablets of Warfarin Prepared by Wet Granulation Technique
}

Sandip R. Pawar*, Anil S. Mahajan, Md. Rageeb Md. Usman, Tanvir Y. Shaikh, Bharat V. Jain

Smt. Sharadchandrika Suresh Patil College of Pharmacy, Chopda, Maharashtra, India.

*Corresponding author's E-mail: drmdrageeb@gmail.com

Received: 01-09-2020; Revised: 24-10-2020; Accepted: 03-11-2020; Published on: 15-11-2020.

\section{ABSTRACT}

The objective of the present study was to develop Warfarin Oral Fast Disintegrating Tablets by using wet granulation techniques which are simple and cost effective such as use of super disintegrant technology. In this study, Polyplasdon $\mathrm{XL}$ and $\mathrm{Crospovid}$ one $\mathrm{CL}$ were used in the rapid disintegration of the tablets. In this various trials were conducted for the selection of optimum concentration of super disintegrants. The optimized formula aids in the stabilization of final product. The blend and compressed tablets were evaluated for physical characteristics like bulk density, tapped density, angle of repose, hardness, friability, disintegration time, Invitro dissolution, content uniformity. From the in vitro disintegration test it was found that in range of 11 to 28 seconds, Optimized F8 has lower disintegration time 11seconds. Based on the dissolution data of all the prepared ODTs, the F8 batch shows $102.6 \%$ drug release in 30 minutes. The Stability Study was conducted for the optimized batch F8 \& found stable. In conclusion, Oral Fast Disintegrating Tablets of Warfarin prepared using wet granulation seems to be promising formulations.

Keywords: Warfarin, Wet granulation, Disintegration time, Polyplasdon XL, Stability Study.

QUICK RESPONSE CODE $\rightarrow$

DOI:

10.47583/ijpsrr.2020.v65i01.023

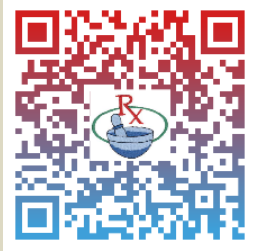

DOI link: http://dx.doi.org/10.47583/ijpsrr.2020.v65i01.023

\section{INTRODUCTION}

D ifficulty in swallowing (Dysphasia) is common among all age groups, especially in elderly, and is also seen in swallowing of conventional tablets and capsules ${ }^{1}$. Geriatric and pediatric patients and travelling patients who may not have ready access to water are most in need of easy swallowing dosage forms ${ }^{2-5}$. $50 \%$ of the population suffers from this problem ${ }^{6}$.

To overcome these problems, mouth dissolving tablets (MDT) have been developed, which having good hardness, dose uniformity, easy administration and serves as the first choice of dosage form for pediatrics, geriatrics and travelling patients. MDTs are also known as "fast-melting, fast-dissolving, oral disintegrating or disperse ${ }^{7-10}$.

Mouth dissolving tablets can define as "A solid dosage form containing medicinal substances, which disintegrates rapidly, usually within a matter of seconds, when placed under the tongue Fast disintegrating drug delivery (FDDTs,) can be achieved by various conventional methods like direct compression, wet granulation, moulding, spray drying, freeze drying, and sublimation. Orodispersible Tablets are also known as mouth disintegrating tablets, melt-in mouth tablets, Orodispersible tablets, porous tablets, quick dissolving tablets, fast dissolving tablets. Mouth Dissolving Tablet has a pleasing mouth feel, and it not required water to swallow. MDT easily dissolved or disintegrates in saliva within a few seconds (15 s to $3 \mathrm{~min}$ ) without the need of drinking water or chewing, leaves no residue in the mouth when administered and less sensitive to environmental conditions like temperature, humidity ${ }^{10-}$ 13 .

\section{MATERIALS AND METHOD}

Warfarin was obtained as a gift sample Maxheal Pharmaceuticals, MIDC, Nashik Polyplasdon XL, Crospovidone CL, Avicel PH 102, PVP K30, Avicel PH 102, Orange, Mannitol, Aspartame, Mg. stearate, Colloidal Silicon Dioxide. From Research Lab Fine Chem. Ltd. Mumbai.

\section{METHODS}

\section{Formulation of Oral Fast Disintegrating Tablets by Wet Granulation $^{14-16}$.}

Weighted and sifted Warfarin, Diluents (Mannitol, MCC) and superdisintegrants Crospovidone $\mathrm{CL}$, Polyplasdone $\mathrm{XL}$ passed through \#40 sieves. Mixed Warfarin and diluents in octagonal blender for 5 minutes. Weighted and Dissolved the binder (PVP K30) into pure water (approximately 25\%). Then slowly add above binder solution into the mix powder in Rapid Mixer Granulator. At last allowed to dry the obtained granules into a tray dryer for around $2 \mathrm{hr}$ at $60^{\circ} \mathrm{C}$ \& passed the drying granules through \#20 sieve. Weighted and sifted Colloidal Silicon Dioxide, Sweetener, Flavors, and Lubricant through 60\# sieve.Mixed all ingredients in poly beg for 5 minutes. Lubricated granules were compressed into tablets using $12 \mathrm{~mm}$ FFBE (Flat Face Bevel Edge) punch set using an eight station tablet press. Compression was carried out using " $B$ " tooling punches sets. 
Table 1: Composition of Oral Fast Disintegrating Tablet Batches

\begin{tabular}{|c|c|c|c|c|c|c|c|c|c|}
\hline Sr. No. & Ingredients (mg/tab) & F1 & F2 & F3 & F4 & F5 & F6 & F7 & F8 \\
\hline 1 & Warfarin & 250 & 250 & 250 & 250 & 250 & 250 & 250 & 250 \\
\hline 2 & Avicel PH 102 & 100 & 100 & 150 & 150 & 150 & 150 & QS & QS \\
\hline 3 & Mannitol & 55 & 55 & - & - & 25 & 25 & - & - \\
\hline 4 & Crospovidon $\mathrm{CL}$ & 25 & - & 35 & - & 25 & - & 35 & 10 \\
\hline 5 & Polyplasdon XL & - & 25 & - & 35 & - & 25 & 5 & 35 \\
\hline 6 & PVP K30 & 25 & 25 & 35 & 35 & - & 25 & 25 & 25 \\
\hline 7 & Colloidal Silicon Dioxide & 5 & 5 & 5 & 5 & 5 & 5 & 5 & 5 \\
\hline 8 & Aspartame & 25 & 25 & 15 & 15 & 10 & 10 & 15 & 15 \\
\hline 9 & Orange Flavour & 10 & 10 & 5 & 5 & 5 & 5 & 15 & 15 \\
\hline 10 & Magnesium Stearate & 5 & 5 & 5 & 5 & 5 & 5 & 5 & 5 \\
\hline \multirow[t]{2}{*}{11} & Purified Water & Q.S. & Q.S. & Q.S. & Q.S. & Q.S. & Q.S. & Q.S. & Q.S. \\
\hline & Net Total & 500.00 & 500.00 & 500.00 & 500.00 & 500.00 & 500.00 & 500.00 & 500.00 \\
\hline
\end{tabular}

Q.S. = Quantity Sufficient

\section{EVALUATION OF PREE AND POST COMPRESSION PARAMETERS OF TABLETS}

\section{Evaluation of Prepared Granules ${ }^{17-18}$.}

\section{Bulk Density}

It refers to packing of particles. Bulk density is used to determine the amount of drug that occupies the volume in $\mathrm{g} / \mathrm{ml}$.

\section{Procedure}

Weighed quantity of Warfarin was transferred into $100 \mathrm{ml}$ measuring cylinder without tapping during transfer. The volume occupied by drug was measured. Bulk density was measured by using formula

\section{Bulk Density $=\mathrm{m} / \mathrm{V}_{\mathrm{i}}$}

Where, $\mathrm{m}=$ mass of the blend

$$
\mathrm{V}_{\mathrm{i}}=\text { untapped volume }
$$

\section{Tapped density}

Weighed quantity of drug was taken into a graduated cylinder. Volume occupied by the drug was noted down. Then the cylinder was subjected to 500,750 \&1250 taps in tap density apparatus (Electro Lab USP II). According to USP, The blend was subjected for 500 taps. \% Volume variation was calculated and subjected for additional 750 taps and \% Variation was calculated.

\section{Tapped density $=m / V_{t}$}

Where, $\mathrm{V}_{\mathrm{t}}$ is tapped volume

\section{Carr's Index (Compressibility):}

The compressibility index and Hausner ratio was measures the property of powder to be compressed. The packing ability of drug was evaluated from change in volume, which is due to rearrangement of packing occurring during tapping. It was indicated as Carr's compressibility index was calculated by following formula,
- Carr's index $=$ [Tapped density - Bulk density/Tapped density] X 100

\section{Hausner Ratio}

It is measurement of frictional resistance of the drug .The ideal range should be 1.2-1.5. It was determined by the ratio of tapped density and bulk density

Hausner Ratio = Tapped density / Bulk density

\section{Angle of Repose}

It is defined as the maximum angle that can be obtained between the free standing of powder heap and horizontal plane, which is determined by the equation:

$$
\theta=\tan ^{-1} \mathrm{~h} / \mathrm{r}
$$

Where, $\theta=$ Angle of repose.

$$
\begin{aligned}
& h=\text { Height of powder heap. } \\
& r=\text { Radius of the powder cone. }
\end{aligned}
$$

\section{Procedure}

Weighed quantity of the drug sample was passed through a funnel kept at a height $2 \mathrm{~cm}$ from the base. The powder was passed till it forms a heap and touches the tip of the funnel. The radius was measured and angle of repose was calculated by using above formula.

\section{Evaluation of Prepared Oral Fast Disintegrating Tablets ${ }^{19-}$ 23 .}

Prepared Oral Fast Disintegrating Tablets were evaluated for the following parameters.

\section{Physical appearance}

The general appearance and elegance of tablet was identified visually, which include tablet size, shape, color, presence or absence of an odor, taste, surface texture and sticking of tablet etc. 


\section{Hardness}

Method: Ten tablets were randomly selected and hardness was measured in Schleuniger hardness tester. The average of 3 readings was taken as hardness of the tablet.

\section{Thickness}

Ten Tablets were selected randomly from individual formulations and thickness was measured by using vernier caliper scale, which permits accurate measurement. The average of 3 readings was taken as thickness of the tablet.

\section{Friability}

Ten tablets were randomly select and weighed (initial wt.) and then transfer into Rocha friabilator. It was subjected to 100 revolutions in 4 minutes. The tablets were dedusted and reweighed (final wt). These two weights (i.e. initial and final) were applied to calculate the friability of tablet.

$$
\begin{aligned}
& \text { (Initial Weight - final weight) }
\end{aligned}
$$

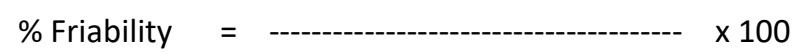

$$
\begin{aligned}
& \text { (Initial weight) }
\end{aligned}
$$

\section{Weight variation}

Twenty tablets were taken randomly, weigh individually and average weight was determined. The individual tablet weight was compared with average tablet weight.

\section{Content Uniformity}

For this at least 20 tablets were randomly selected. 20 tablets were crushed into fine powder and assayed individually; the content uniformity of drug should be within $90 \%$ to $110 \%$ of the labeled claim.

\section{Disintegration test}

In vitro disintegration time was measured using USP disintegration test apparatus. For DT test randomly six tablets were selected from each batch and test was performed in $900 \mathrm{ml}$ distilled water at $37 \pm 0.5{ }^{\circ} \mathrm{C}$ temperatures and at the rate of $30 \pm 2$ cycles $/ \mathrm{min}$.

\section{Dissolution study}

\section{Dissolution}

Medium: pH 5.8 phosphate buffer (see Buffer Solutions in the section $900 \mathrm{~mL}$.USP II apparatus at $50 \mathrm{rpm}$.

Time: 30 minutes.

Procedure - One tablet was placed in each dissolution vessel and the paddle rotation speed was set at 50rpm. $10 \mathrm{ml}$ of the sample was withdrawn at the intervals of 0,5 , $10,15,30 \mathrm{~min}$ and the same volume of the fresh medium was replaced every time. The samples were analyzed for drug content at a wavelength of $243 \mathrm{~nm}$ using double beam UV-Visible spectrophotometer. The content of the drug was calculated using the equation generated from the standard curve. The percentage cumulative drug released was calculated.

\section{Stability Study of Optimized Formulation F8}

Stability testing done at $40^{\circ} \mathrm{C} / 75 \% \mathrm{RH}$ for 1 month.

\section{RESULTS AND DISCUSSION}

Table 2: Pre compression property of API \& optimized Batch

\begin{tabular}{|c|c|c|c|}
\hline Sr. No. & Parameters & API & $\begin{array}{c}\text { Optimized } \\
\text { batch F8 }\end{array}$ \\
\hline 1. & Bulk Density & $0.353 \mathrm{gm} / \mathrm{ml}$ & $0.418 \mathrm{gm} / \mathrm{ml}$ \\
\hline 2. & $\begin{array}{r}\text { Tapped } \\
\text { Density }\end{array}$ & $0.706 \mathrm{gm} / \mathrm{ml}$ & $0.514 \mathrm{gm} / \mathrm{ml}$ \\
\hline 3. & $\begin{array}{c}\text { Carr's index } \\
\text { Hausner Ratio }\end{array}$ & $50 \%$ & 18.6 \\
\hline 5. & $\begin{array}{r}\text { Angle of } \\
\text { Repose }\end{array}$ & 36 & 1.2 \\
\hline
\end{tabular}

\section{Evaluation of Oral Fast Disintegrating Tablets}

\section{Physical appearance}

The general appearance and elegance of tablet was identified visually, prepared tablets have absence of an odor, smooth surface texture and no sticking seen in tablet etc.

\section{Weight variation}

The weight of all the tablets was found within the range of $500 \pm 5 \mathrm{mg}$. Hence, the weight of all formulations was found within the limit

\section{Hardness}

Hardness of the formulations F1-F8 was observed within the range of $2.4-3.1$ to $3.5-3.7 \mathrm{~kg} / \mathrm{cm}^{2}$ as shown in Table 3 .

\section{Thickness}

The thickness of all the tablets was found within the range 5.41 to $5.88 \mathrm{~mm}$.

\section{Friability}

The percent friability of all the prepared formulae was $<1 \%$. The previous results indicated that all formulations complied with the pharmacopeias limits for these tests.

\section{Drug content}

The drug content was found to be uniform for all the prepared formulations and was found to be within the range of 96.61 to $99.32 \%$.

\section{Disintegration test}

From the in vitro disintegration test it was found that in range of 11 to 28 seconds, Optimized F8 has lower disintegration time 11 seconds. 
Table 3: Physical Parameter of batch F1 to F8

\begin{tabular}{|c|c|c|c|c|}
\hline Batch & Weight variation $(\mathbf{m g})$ & Hardness $(\mathbf{k p})$ & Disintegrating time (sec) & Friability (\%) \\
\hline F1 & 496 & $2.5-3.5$ & 28 & 0.14 \\
\hline F2 & 496 & $2.4-3.5$ & 22 & 0.18 \\
\hline F3 & 500 & $2.5-3.3$ & 18 & 0.15 \\
\hline F4 & 504 & $3.5-3.7$ & 12 & 0.68 \\
\hline F5 & 501 & $2.5-3.2$ & 16 & 0.21 \\
\hline F6 & 500 & $2.2-3.4$ & 12 & 0.15 \\
\hline F7 & 499 & $2.5-3.5$ & 16 & 0.16 \\
\hline
\end{tabular}

\section{In vitro dissolution study}

Dissolution study performed as per USP method. One tablet was placed in each dissolution vessel and the paddle rotation speed was set at $50 \mathrm{rpm} .10 \mathrm{ml}$ of the sample was withdrawn at the intervals of $0,5,10,15,30 \mathrm{~min}$ and the same volume of the fresh medium was replaced every time. The samples were analyzed for drug content at a wavelength of $243 \mathrm{~nm}$.

In vitro Dissolution test: Based on the dissolution data of all the prepared ODTs, the F8 batch shows $102.6 \%$ drug release in 30 minutes.

Table 4: Dissolution study of Batch F1 to F8

\begin{tabular}{|c|c|c|c|c|c|c|c|c|}
\hline Time (min) & F1 & F2 & F3 & F4 & F5 & F6 & F7 & F8 \\
\hline 0 & 0 & 0 & 0 & 0 & 0 & 0 & 0 & 0 \\
\hline 5 & $88.0 \pm 0.5$ & $87.9 \pm 0.9$ & $70.8 \pm 0.2$ & $69.9 \pm 0.6$ & $84.7 \pm 0.2$ & $85.9 \pm 0.2$ & $92.3 \pm 0.3$ & $89.5 \pm 0.2$ \\
\hline 10 & $99.9 \pm 0.4$ & $95.8 \pm 0.8$ & $86.9 \pm 0.6$ & $77.8 \pm 0.5$ & $98.9 \pm 0.3$ & $96.5 \pm 0.6$ & $98.0 \pm 0.2$ & $98.4 \pm 0.5$ \\
\hline 15 & $103.5 \pm 0.6$ & $100.1 \pm 0.6$ & $90.6 \pm 0.5$ & $86.9 \pm 0.2$ & $99.2 \pm 0.2$ & $98.7 \pm 0.3$ & $99.2 \pm 0.5$ & $99.8 \pm 0.4$ \\
\hline 20 & $104.8 \pm 0.7$ & $102.9 \pm 0.2$ & $95.8 \pm 0.2$ & $93.9 \pm 0.3$ & $102.9 \pm 0.1$ & $102.1 \pm 0.4$ & $100.3 \pm 0.3$ & $100.5 \pm 0.2$ \\
\hline 30 & $103.5 \pm 0.4$ & $105.0 \pm 0.3$ & $99.3 \pm 0.6$ & $95.9 \pm 0.3$ & $105.7 \pm 0.7$ & $108.8 \pm 0.4$ & $101.2 \pm 0.4$ & $102.6 \pm 0.5$ \\
\hline
\end{tabular}

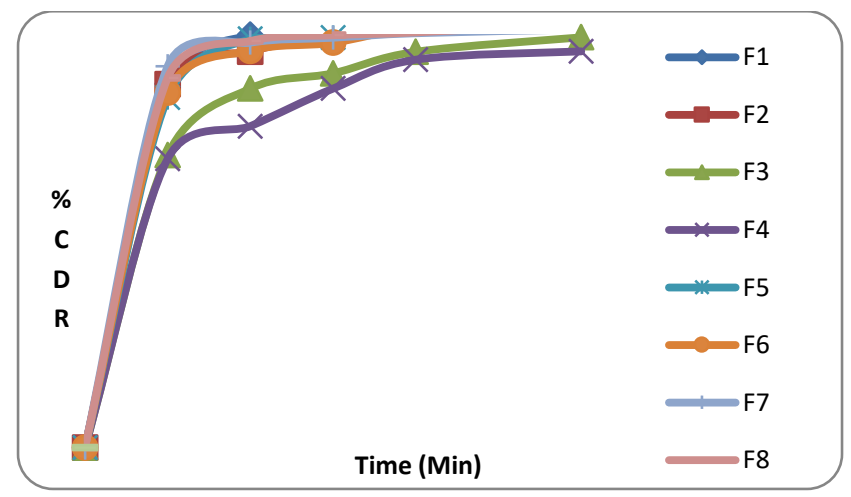

Figure 1: In vitro release of Warfarin from tablets of F1 to F8

\section{Stability Studies of Optimized F8 Formulation}

Table 5: Comparison profile of stability batch $\mathrm{F} 8$, initial and 1 month

\begin{tabular}{|c|c|c|}
\hline \multirow[t]{2}{*}{ Parameter } & \multicolumn{2}{|c|}{$\begin{array}{c}\text { Condition } \\
\left(40^{\circ} \mathrm{C} \pm 2^{\circ} \mathrm{C} / 75 \% \pm 5 \% \mathrm{RH}\right)\end{array}$} \\
\hline & Initial (F8) & (F8) After 1 month \\
\hline Hardness (Kp) & $2.5-3.0$ & $2.5 \pm 2.9$ \\
\hline Friability (\%w/w) & $0.15 \pm 0.7$ & $0.15 \pm 0.45$ \\
\hline Disintegration time (sec) & $11 \pm 3$ & $11 \pm 2$ \\
\hline
\end{tabular}

\section{CONCLUSION}

In the present work, fast dissolving tablets of Warfarin were prepared by wet granulation methods using superdisintegrants such as Polyplasdon $\mathrm{XL}$, and Crospovidone $\mathrm{CL}$. All the tablets of Warfarin were subjected to tests for weight variation, hardness, friability, in vitro disintegration time, drug content uniformity, and in vitro drug release. All parameters are in acceptable limit. Based on the dissolution data of all the prepared ODTs, the F8 batch shows $102.6 \%$ drug release in 30 minutes. . The stability study was conducted for the optimized batch F8 and result shows formulation are stable in stability study. In conclusion, Oral Fast Disintegrating Tablets of Warfarin prepared using wet granulation seems to be promising formulations.

\section{REFERENCES}

1. Baichwal MR, Moghe $B D$, Modified cellulose as tablet disintegrant, Indian Journal of Pharmacy, 33 (1), 1971, 2931.

2. Borodkin S, Yunker MH, Interaction of amino drugs with the polycarboxilic acid ion exchange resin, Journal of Pharmacy, 98 (11), 1970, 3886-3902. 
3. Chatap V, Sharma D, Middha A, Gupta R, Saini V, Shiradkar $M$, Mouth Disintegrating Tablets of Taste-masked Ondansetron Hydrochloride, Asian Journal of Chemistry, 19 (2), 2007, 3455-3460.

4. Gosai A, Patil S, Sawant K, Formulation and Evaluation of Oro Dispersible Tablets of Ondansetron Hydrochloride by Direct Compression using Superdisintegrants, International Journal of Pharmaceutical Sciences and Nanotechnology, 1 (1), 2008, 106-111.

5. Jacob S, Shiwaikar A, Joseph A, Shrinivasan K, Novel coprocessed excipients of mannitol and microcrystalline cellulose for preparing fast dissolving tablets of Glipizide', Indian Journal of Pharmaceutical Sciences, 27 (1), 2007, 633639 .

6. Katdare A, Chaubal $M$, Excipient development for pharmaceutical biotechnology and drug delivery systems, Informa Healthcare, New York, 1-3.

7. Khan $S$, Nakhat $P$, Yeole $P$, Kataria $P$, Taste masking of Ondansetron hydrochloride by polymer carrier system and formulation of rapid disintegrating tablets, AAPS, Pharmaceutical Science Technology, 8 (2), 2007, E1-E2.

8. Koizumi K, Yoshiteru W, New Method for Preparing HighPorosity Rapid Saliva- Soluble Compressed Tablets Using Mannitol with Camphor a Subliming Material, International Journal of Pharmaceutics, 152 (2), 1997, 127-131.

9. Kulkarni $M$, Zeeshan A, Bhise K, Somwanshi S, Formulation and Evaluation of Orodispersible Tablet of Ornidazole, International Journal of Studies and Research, 1 (1), 2009, 39-47.

10. Madgulkar AR, Bhalekar, Formulation Design and Optimization of Novel Taste Masked Mouth-Dissolving Tablets of Tramadol Having Adequate Mechanical Strength, AAPS Pharmaceutical Science Technology, 10 (2), 2009, 574581.

11. Margret C, Jaykar B, Chakrabarty B, Formulation and evaluation of Orodispersible tablets of terbutaline sulphat, Drug Invention today, 1 (1), 2010, 31-33.

12. Modi A, Tayade P, Enhancement of dissolution profile by solid dispersion (kneading) technique, Pharmaceutical Science Techniques, 7 (3), 2006, 68.

13. Morita $Y$, Yukiyasui $M$, Masanob U, Ryojiajioka K, Junkotak A, Evaluation of the disintegration time of rapidly disintegrating tablets via a novel method utilizing a CCD camera, Chemical \& Pharmaceutical Bulletin, 50 (9), 2002, 1181-1186.

14. Makwana SH, Patel L, Patel T, Formulation and Evaluation of Taste Masked Orodispersible Tablet of Ondansetron Hydrochloride, Pharmaceutical Journal of Science and Research, 2 (2), 2010, 232-239.

15. Puttewara T, Kshirsagar M, Chandewar A, Chikale $R$, Formulation and evaluation of taste masked Orodispersible tablet of doxilamine succinate using ion exchange resin, Journal of King Saud University- Science, 22 (4), 2010, 229240.

16. Shangraw RF, Mitrevej AM, Shah MN A new era of tablet Disintegrants, Pharmaceutical Technology, 4 (2), 1980, 4957.

17. Shishu S, Bhatti A, Singh $T$, Preparation of tablets rapidly disintegrating in saliva containing bitter taste-masked granules by compression method, Indian Journal of Pharmaceutical Sciences, 16 (3), 2007, 80-84.

18. Swamy P, Gada S, Shirsand S, Kinagi B, Shilpa H, Design and Evaluation of Cost Effective Orodispersible Tablet of Diethyl Carbamazine Citrate by Effervescent Method, Pharmaceutical journal of Science and Research, 1 (1), 2010, 258-264.

19. Reddy L, Ghosh B, Rajneesh, Fast dissolving drug delivery systems: a review of the literature, Indian Journal of Pharmaceutical Sciences, 64 (4), 2002, 331-336.

20. Ringard J, Guyot-Hermann A, Calculation of disintegrant critical concentration in order to optimize tablet disintegration, Drug development and Industrial Pharmacy, 14 (5), 1988, 2321-2339.

21. Venktesh D, Jha S, Karki R, Formulation Development and Evaluation of Taste Masked ORO-dispersible tablet of antiemetic drug, Journal of Pharmacy Research, 2 (4), 2009, 606609.

22. Venktesh D, Rao G, Formulation of Oro-dispersible tablet of Ambroxol Hydrochloride, Asian Journal of Pharmaceutics, 2 (4), 2008, 261-264.

23. Yunixia B, Sunada H, Yonezawa Y, Danjo K, Evaluation of rapidly disintegrating tablet prepared by direct compression method, Drug Development and Industrial Pharmacy, 25 (5), 1999, 571-581.

\section{Source of Support: None declared.}

Conflict of Interest: None declared.

For any question relates to this article, please reach us at: editor@globalresearchonline.net New manuscripts for publication can be submitted at: submit@globalresearchonline.net and submit_ijpsrr@rediffmail.com 